\title{
Correlation between Circulating Levels of Pro-Inflammatory Cytokines TNF- $\alpha$ and Vascular Calcification Inhibitor Matrix Gla Protein in Obese Men
}

\author{
Trilis Yulianti ${ }^{1,2}$, Mansyur Arief ${ }^{3}$, and Andi Wijaya ${ }^{1,2}$ \\ 1Prodia Clinical Laboratory \\ ${ }^{2}$ Post Graduate Program, in Biomedical Science Hasanuddin University \\ ${ }^{3}$ Faculty of Medicine, Hasanuddin University
}

\section{Abstract}

\section{$\mathrm{B}$} ACKGROUND: Adult obesity is rapidly increasing in the world including Indonesia. Tumor necrosis factor $\alpha$ (TNF- $\alpha$ ) was chronically elevated in obese adipose tissue. TNF- $\alpha$, a pleiotropic cytokine and also a regulator of bone formation, may might represent an important link between obesity and vascular calcification. Elegant genetic studies in mice and human have highlighted the important roles for Matrix Gla Protein (MGP) as an inhibitor of vascular calcification. The aim of this study was to examine the correlation between circulating levels of pro-inflammatory cytokines TNF- $\alpha$ and vascular calcification inhibitor MGP in obese men.

METHODS: This was an observational cross sectional study including 40 central obese men (waist circumference $\geq 90 \mathrm{~cm}$ ) aged 31-60 years old. Serum MGP and serum TNF- $\alpha$ concentrations were quantified by ELISA principle. Fasting plasma glucose was assessed using hexokinase methods, triglyceride by GPO-PAP methods, and creatinine by Jaffe methods. All assays were performed according to the manufacture instruction.

Statistical analysis was performed with SPSS for windows ver 16 . Univariate analysis were performed to analyze mean, maximum, minimum value and SD. Pearson correlation statistic were performed to determine the correlation between variables. Significance value were define as alpha level $=0.05$ based on two-tailed tests.
RESULTS: The cross-sectional study $(\mathrm{n}=40)$ showed that the advancing age was correlated with plasma TNF- $\alpha$ concentration $(r=0.348 ; p=0.028)$. The mean concentration of TNF- $\alpha$ and MGP were 8.323 and 8.368 , respectively. We found a significant negative correlation between TNF- $\alpha$ with MGP ( $\mathrm{r}=-0.425 ; \mathrm{p}=0.006$ ) and a significant correlation between TNF- $\alpha$ and triglyceride $(\mathrm{r}=0.375 ; \mathrm{p}=0.017)$.

CONCLUSIONS: Circulating level of TNF- $\alpha$ was inversely correlated with MGP concentration in obese men. This finding suggested that high level TNF- $\alpha$ leads to low MGP concentration obese men, hence, limits inhibitory capacity in vascular calcification.

KEYWORDS: hypertension, obesity, vascular calcification, MGP, TNF- $\alpha$.

\section{Introduction}

Obesity is a major contributor to the global burden of chronic disease and disability. In developing countries like Indonesia, data from national basic health research 2007 showed that over nutrition was found among all age groups, on a double digit scale, with similar magnitude in urban and rural areas.(1)

Obesity is a major risk factor for cardiovascular disease, and adipocyte-derived factors might contribute 
to or ameliorate obesity-associated pathologies such as vascular dysfunction and a chronic inflammatory state.(2)

Increased plasma levels of the primary inflammatory cytokine TNF- $\alpha$, have been demonstrated in patients with obesity. There is evidence to support the synthesis of TNF- $\alpha$ in adipose tissue. This may contribute to both the maintenance of a chronic low-grade inflammatory state in obese patients. Thus inflammation may be involved in the triggering of vascular calcification. TNF- $\alpha$ has a particular interest in vascular calcification because it has been found to promote osteogenic differentiation and calcification of vascular cells. It may potentially lead to a positive feedback loop, further stimulating macrophage activation and calcification. (3).Although, TNF- $\alpha$ has been detected in both human and mouse atherosclerotic lesions, its contribution to vascular calcification has not been assessed.

Vascular calcification was once considered only a passive process of dead and dying cells, worked from laboratories worldwide has now highlighted that arterial biomineralization is an actively regulated form of calcified tissue metabolism.(4) Genetic and biochemical studies have established MGP as the first protein known to act as a calcification inhibitor in vivo. The role of MGP in calcification is complex. MGP functions as a noggin-like protein by inhibiting BMP/BMPR2 interactions as well as by binding BMP2 directly. Once the BMPR 2 and BMPR1 receptors interact through ligand binding its downstream effects are achieved through the upregulation of key osteogenic transcription factors including Msx2, Cbfa1, and osterix. Expression of transcription factors in VSMCs serves as an early initial step in vascular calcification. (5) Association between TNF- $\alpha$ and MGP is unknown. Present study aim to examine correlation between TNF- $\alpha$ and MGP.

\section{Methods}

This study protocol has been approved by the institutional review boards: the ethical clearance from the Health Research Ethics Committee Faculty of Medicine Padjajaran University Dr Hasan Sadikin General Hospital Bandung, (No: 25/FKUP-RSHS/KEPK/Kep/EC/2008). All participants provided written informed consent.

This study included 40 Indonesian obese men (waist circumferences $\geq 90 \mathrm{~cm}$ ) aged 31-60 years. Subject with symptoms of infection, or any underlying acute inflammation were excluded. Heights, body weights, blood pressure and waist circumferences were measured by standard methods and the body mass index (BMI) was calculated according to the standard formula.

\section{ASSAY OF BIOCHEMICAL MARKERS Serum handling}

Blood was collected by venipuncture in serum tubes (10 $\mathrm{ml}$; BD Vacutainer Systems) and in sodium citrate $(10 \mathrm{ml}$; BD Vacutainer Systems) and stored for $20 \mathrm{~min}$ at room temperature before centrifugation. Serum and plasma were sub sampled in aliquots and frozen at $-70^{\circ} \mathrm{C}$ until test were performed.

Serum MGP concentrations were quantified with Human MGP Matrix GLA Protein kit (Biomedica Vienna, Austria), based on the competitive ELISA principle, where antibodies against non-phosphorylated MGP coated on the microtiter plate as has been described before. Serum TNF- $\alpha$ concentrations were quantified with the kit from IMMULITE 1000 TNF- $\alpha$ based on ELISA principle.

Measurements of fasting plasma glucose was carried out by hexokinase methods (Roche diagnostics), triglyceride with GPO-PAP methods (Roche diagnostics), creatinine by Jaffe methods. All assays were performed according to manufacturers instruction.

\section{STATISTICAL ANALYSIS}

Statistical analysis was performed using SPSS for windows ver 16. Univariate analysis were performed to analyze mean, maximum and minimum value and SD. Pearson correlation statistic were performed to determined the correlation between variables. Significance value were define as alpha level 0.05 based on two-tailed tests.

\section{Results}

Subjects characteristics including age, body mass index, waist circumference, blood pressure, creatinine serum, cholesterol HDL, Triglyceride, MGP and TNF $\alpha$ were shown in Table 1. According to the data shown in Table 1 , there were no outliers data, showed from the standard deviation values which were lower than the mean values.

We found a positive correlation in this study between age and TNF- $\alpha(r=0.348 ; p=0.028)$, also a significant negative correlation between TNF- $\alpha$ and MGP $(r=-0.425$; $\mathrm{p}=0.006$ ). This study also showed a significant correlation between TNF- $\alpha$ and triglyceride $(r=0.375 ; \mathrm{p}=0.017)$ (Table 2). We found no significant correlation between MGP and all variables except TNF- $\alpha$. 
Table 1. Characteristics of 40 patients with obese investigated in the present study.

\begin{tabular}{lrll}
\hline Variable & Mean & \pm SD \\
\hline Age (years) & 46.325 & \pm 7.166 \\
Body Mass Index & 27.989 & \pm 3.403 \\
Waist Circumference $(\mathrm{cm})$ & 99.638 & \pm 6.129 \\
Systolic Blood Pressure $(\mathrm{mmHg})$ & 133.750 & \pm 15.922 \\
Diastolic Blood Pressure $(\mathrm{mmHg})$ & 95.500 & \pm 11.972 \\
Creatinine $(\mathrm{mg} / \mathrm{dL})$ & 0.898 & \pm 0.142 \\
Glomerular Filtration Rate $\left(72 \mathrm{ml} / \mathrm{min} / 1.72 \mathrm{~m}^{2}\right)$ & 115.023 & \pm 21.065 \\
Fasting Plasma Glucose $(\mathrm{mg} / \mathrm{dL})$ & 101.200 & \pm 43.787 \\
Cholesterol-HDL $(\mathrm{mg} / \mathrm{dL})$ & 41.375 & \pm 8.356 \\
Triglyceride $(\mathrm{mg} / \mathrm{dL})$ & 199.025 & \pm 145.345 \\
MGP $(\mathrm{nmol} / \mathrm{L})$ & 8.368 & \pm 1.005 \\
TNF- $\alpha(\mathrm{pg} / \mathrm{mL})$ & 8.323 & \pm 4.351 \\
& &
\end{tabular}

Table 2. Correlation between MGP, TNF- $\alpha$ and other parameters in present study

\begin{tabular}{lcc}
\hline Variable & MGP $(\mathrm{nmol} / \mathrm{L})$ & $\begin{array}{c}\text { TNF- } \alpha(\mathrm{pg} / \mathrm{mL}) \\
\mathbf{r}\end{array}$ \\
\hline Age (years) & -0.220 & $0.348^{\star}$ \\
Body Mass Index & 0.171 & -0.249 \\
Waist Circumference $(\mathrm{cm})$ & 0.117 & -0.170 \\
Systolic Blood Pressure $(\mathrm{mmHg})$ & 0.278 & 0.028 \\
Diastolic Blood Pressure $(\mathrm{mmHg})$ & 0.087 & 0.055 \\
Creatinine (mg/dL) & 0.010 & 0.089 \\
Glomerular Filtration Rate $\left(72 \mathrm{ml} / \mathrm{min} / 1.72 \mathrm{~m}^{2}\right)$ & 0.118 & -0.347 \\
Fasting Plasma Glucose $(\mathrm{mg} / \mathrm{dL})$ & -0.082 & 0.134 \\
Cholesterol-HDL $(\mathrm{mg} / \mathrm{dL})$ & 0.087 & -0.296 \\
Triglyceride $(\mathrm{mg} / \mathrm{dL})$ & -0.187 & $0.375^{\star}$ \\
MGP (nmol/L) & & $-0.425^{\star \star}$ \\
\hline
\end{tabular}

${ }^{\text {*p}}$-value $<0.05$

${ }^{* x}$ p-value $<0.01$ 


\section{Discussions}

\section{Correlation between Age and TNF - $\alpha$}

Our study demonstrated that plasma TNF- $\alpha$ concentration was positively correlated with advancing age $(r=0.348 ; p$ $=0.028$ ). These results were similar to studies performed by Chorinchath et al. (6), Han et al. (7), and Morin et al.(8) which were showed that plasma TNF- $\alpha$ level was increased with advancing age in mice. Cross-sectional study by Paolisso et al. showed that advancing age was correlated with plasma TNF- $\alpha$ concentration $(\mathrm{r}=0.64, \mathrm{P}$ $<0.001)$.(9)

Why plasma TNF- $\alpha$ concentration increases with advancing age remains to be determined. Our volunteers were obese men subjects. Most likely, plasma TNF- $\alpha$ concentration parallels the age-related increasing in body fatness. In our study, the relationship between plasma TNF- $\alpha$ and age was assessed only by a cross-sectional design, so a cause-effect relationship cannot be drawn.

\section{Correlation between $T N F-\alpha$ and serum triglyceride}

In our study found the significant positive correlation between TNF- $\alpha$ and triglyceride $(r=0.375 ; \mathrm{p}=0.017$ ) (Table 2). Other study in rats by Feingold et al. showed that TNF- $\alpha$ administration can promote serum triglycerides level. TNF- $\alpha$ induced hyperlipidemia was suggested to be the result of increasing hepatic lipogenesis and lipolysis rather than decreased peripheral clearance (10). In our study, a significant positive correlation between TNF- $\alpha$ and triglyceride $(r=0.375 ; \mathrm{p}=0.017)$ strengthen the role of cytokines in inducing hyperlipidemia.

\section{Correlation between TNF- $\alpha$ and MGP}

TNF- $\alpha$ a pleiotropic cytokine, has been shown to play a role in both vascular and bone pathophysiology. TNF- $\alpha$ is mainly secreted by macrophages in response to factors such as oxidized LDL (11), acetylated LDL (12), physically damaged extracellular matrix (13), or bacterial infection (14). In vivo, TNF- $\alpha$ induces arteriosclerosis-like lesions in coronary arteries (15). TNF- $\alpha$ also regulates bone turnover, inhibiting osteoblastic function $(16,17,18)$ and stimulating bone resorption (19).

The previous study by Tintut et al. showed that TNF- $\alpha$ enhanced in vitro calcification of vascular cells, providing further evidence that vascular and bone calcification shares regulatory factors. (20) Other study by Jono et al. reported an association between serum MGP levels and coronary artery calcification, detected by EBCT, in 115 subjects with suspected coronary artery disease and normal renal function. Patients with coronary artery calcification had lower serum MGP levels compared to those with no calcium in the coronary tree, suggesting the potential role of MGP on prevention of vascular calcification.(21)

Our data demonstrated a significant negative correlation between MGP and TNF $\alpha$ ( $\mathrm{r}=-0.425$; $\mathrm{p}=$ $0.006)$. This result suggested that elevated plasma TNF- $\alpha$ and decreased MGP might provide a further contribution to the calcification of vascular in obese male. However, the relationship between inflammation and MGP insufficiency was less clear. In a series studies, Yao et al. identified that MGP was a Gla-dependent inhibitor of BMP2 and BMP4, an osteogenic morphogens that upregulate AKP2 expression. $(22,23,24)$ Yao et al. went on to show that interleukin (IL) 6 , an inflammatory cytokine that was important in diabetic vascular diseases, increased the expression and secretion of heat shock protein (HSP) 70 , an endogenous MGP binding protein and antagonist of MGP function that was highly expressed in calcifying atherosclerotic plaques. Thus, by inducing HSP70, inflammatory signals could potentiate vascular BMP2/4 actions by nullifying MGP.(24)

\section{Conclusions}

Circulating level of TNF- $\alpha$ was increase and MGP concentration was decrease in obese men. This finding suggested that high level of TNF- $\alpha$ leads to low MGP concentration in obese men, hence, limiting the inhibitory capacity in vascular calcification.

Further studies were needed to elucidate the mechanisms of TNF- $\alpha$ in suppressing MGP as a novel link in vascular calcification.

\section{References:}

1. Usfar AA, Lebenthal E, Atmarita, Achadi E, Soekirman, Hadi H. Obesity as a poverty-related emerging nutrition problems: the case of Indonesia. Obes Rev. 2010; 11(12): 924-8.

2. Ruth E Gimeno and Lori D Klaman. Adipose tissue as an active endocrine organ: recent advances. Curr Opin Pharmacol 2005; 5: 122-8.

3. Kristina Boström. Proinflammatory vascular calcification. Circ Res 2005; 96: 1219-20.

4. Jian-Su Shao, Su-Li Cheng, Justin Sadhu and Dwight A. Towler. Inflammation and the osteogenic regulation of vascular calcification: A review and perspective. Hypertension 2010; 55: 579-92.

5. Jonson RC, Leopold JA and Loscalzo J. Vascular calcification: 
pathobiological mechanisms and clinical implications. Circ. Res 2006; 99: 1044-59.

6. Chorinchath, B. B., L.Y. Kong, L. Mao, and R. E. McCallum. Ageassociated differences in TNF- $\alpha$ and nitric oxide production in endotoxic mice. J. Immunol 1996; 156: 1525-30.

7. Han, D., T. Hosokawa, A. Aoike, and K. Kawai. Age-related enhancement of tumor necrosis factor production in mice. Mech Ageing Dev 1995; 84: 39-54.

8. Morin, C. L., M. J. Pagliasotti, D. Windmiller, and R. H. Eckel. Adipose tissue-derived tumor necrosis factor-alpha is elevated in older rats. J Gerontol 1997; 52: B190-5.

9. Paolisso G, Rizzo MR, Mazziotti G, Tagliamonte MR, Gambardella A, Rotondi M, et al. Advancing age and insulin resistance: role of plasma tumor necrosis factor- $\alpha$. Am J Physiol Endocrinol Metab 1998: 275: E294-9.

10. Feingold KR. and Grufeld C. Role of cytokines in inducing hyperlipidemia. Diabetes 1992; 41 (Suppl 2): 97-101.

11. Jovinge $\mathrm{S}$, Ares MP and Kallin B. Human monocytes/ macrophages release TNF- $\alpha$ in response to ox-LDL. Arterioscler Thromb Vasc Biol. 1996; 16: 1573-79.

12. Barath $P$, Cao J, Forrester JS. Low density lipoprotein activates monocytes to express tumor necrosis factor. FEBS Lett. 1990; 277: 180-4.

13. Hershkoviz R, Cahalon L and Gilat D. Physically damaged extracellular matrix induces TNF-a secretion by interacting resting CD41 T cells and macrophages. Scand J Immunol. 1993; $37: 111-5$

14. Mizutani $H$, Ohmoto $Y$, Mizutani $T$, Murata $M$, and Shimizu M. Role of increased production of monocytes TNF- $\alpha$, IL-1 $\beta$ and IL-6 in psoriasis: relation to focal infection, disease activity and responses to treatments. J Dermatol Sci 1997; 14: $145-53$

15. Fukumoto $\mathrm{Y}$, Shimokawa $\mathrm{H}$, and Ito $\mathrm{A}$. Inflammatory cytokines cause coronary arteriosclerosis-like changes and alterations in the smooth muscle phenotypes in pigs. J Cardiovasc Pharmacol 1997; 29: 222-31.
16. Panagakos FS, Fernandez $\mathrm{C}$, Kumar $\mathrm{S}$. Ultrastructural analysis of mineralized matrix from human osteoblastic cells: effect of tumor necrosis factor-a. Mol Cell Biochem. 1996; 158 : $81-9$.

17. Mayur N, Lewis S and Catherwood BD. Tumor necrosis factor alpha decreases 1,25-dihydroxyvitamin D3 receptors in osteoblastic ROS 17/2.8 cells. J Bone Min Res 1993; 8: 997-1003.

18. Rosenquist JB, Ohlin A, Lerner UH. Cytokine-induced inhibition of bone matrix proteins is not mediated by prostaglandins. Inflammation Res 1996; 45: 457-63.

19. Bertolini DR, Nedwin GE, Bringman TS, Smith DD, and Mundy GR. Stimulation of bone resorption and inhibition of bone formation in vitro by human tumor necrosis factors. Nature 1986; 319: 516-8

20. Tintut Y, Patel J, Parhami F and Demer LL. Tumor Necrosis Factor- $\alpha$ promotes in vitro calcification of vascular cells via the cAMP pathway. Circulation 2000; 102: 2636-42.

21. Jono $S$, Ikari $Y$, Vermeer $C$, Dissel $P$, Hasegawa $K$, Shioi $A$ et al. Matrix Gla protein is associated with coronary artery calcification as assessed by electron-beam computed tomography. Thromb Haemost 2004; 91: 790-4

22. Yao $\mathrm{Y}$, Watson $\mathrm{AD}$, Ji S, Bostrom $\mathrm{KI}$. Heat shock protein 70 enhances vascular bone morphogenetic protein-4 signaling by binding matrix Gla protein. Circ Res. 2009; 105: 57584.

23. Zebboudj AF, Shin V, Bostrom K. Matrix GLA protein and BMP-2 regulate osteoinduction in calcifying vascular cells. J Cell Biochem. 2003; 90: 756-65.

24. Yao Y, Shahbazian A, Bostrom Kl. Proline and gammacarboxylated glutamate residues in matrix Gla protein are critical for binding of bone morphogenetic protein-4. Circ Res. 2008; 102: 1065-74. 